\title{
Effects of human vascular endothelial growth factor on reparative dentin formation
}

\author{
JUAN ZHANG ${ }^{1}$, XIA LIU $^{1}$, WEIXIAN YU ${ }^{1}$, YINGLI ZHANG ${ }^{1}$, CE SHI $^{1}$, SHILEI NI ${ }^{1}$, QILIN LIU ${ }^{1}$, \\ XIANGWEI LI ${ }^{1}$, YINGJIAN SUN ${ }^{2}$, CHANGYU ZHENG ${ }^{3}$ and HONGCHEN SUN ${ }^{1}$ \\ ${ }^{1}$ The Key Laboratory of Tooth Development and Bone Remodeling, Jilin Hospital of Stomatology, Jilin University; \\ ${ }^{2}$ Department of Ophthalmology, The Second Hospital of Jilin University, Changchun, Jilin 130021, P.R. China; \\ ${ }^{3}$ Molecular Physiology and Therapeutics Branch, National Institute of Dental and Craniofacial Research, \\ National Institutes of Health, Bethesda, MD 20892, USA
}

Received January 20, 2015; Accepted November 5, 2015

DOI: $10.3892 / \mathrm{mmr} .2015 .4608$

\begin{abstract}
It is a challenge for dentists to save dental pulp in patients with pulp disease without resorting to root canal therapy. Formation of tertiary dentin to maintain pulp vitality is a key odontoblast response to dental pulp injury. Vascular endothelial growth factor (VEGF) is the most potent angiogenic and vasculogenic factor involved in tertiary dentin formation. It was hypothesized that VEGF may be used to treat pulp diseases such as pulpitis. To explore this hypothesis, the first step was to assess whether VEGF affects dental pulp cells to promote reparative dentin formation. In the current study, an AdCMV-hVEGF vector was constructed to deliver hVEGF into dental pulp cells of exfoliated deciduous teeth (hDPCs) in vitro and dental pulp cells in a rat model in vivo. The collected data clearly demonstrated that hVEGF increased alkaline phosphatase and mineralization by enzymatic activity. RT-qPCR data demonstrated that hVEGF significantly increased the expression levels of genes commonly involved in osteogenesis/odontogenesis. Data from the in vivo assays indicated that hVEGF enhanced pulp cell proliferation and neovascularization, and markedly increased formation of reparative dentin in dental pulp. The in vitro and in vivo data suggest that hVEGF may have potential clinical applications, thus may aid in the development of novel treatment strategies for dental pulpitis.
\end{abstract}

Correspondence to: Dr Hongchen Sun, The Key Laboratory of Tooth Development and Bone Remodeling, Jilin Hospital of Stomatology, Jilin University, 1500 Qinghua Road, Changchun, Jilin 130021, P.R. China

E-mail: hcsun@mail.jlu.edu.cn

Key words: VEGF, formation of reparative dentin, dental pulp cells, gene therapy, mineralization

\section{Introduction}

It is a challenge for dentists to save dental pulp in patients with pulp disease without resorting to root canal therapy. Pulp disease is not a potentially fatal disease, however markedly affects the quality of life of those affected, and recovering damaged pulp remains to be a challenge for dentists. Formation of tertiary dentin to maintain pulp vitality is a key odontoblast response to dental pulp injury $(1,2)$. At present, root canal therapy is a one of the main treatment modalities used for the majority of pulp diseases, which involves the removal of all pulp tissue and leaves an empty tooth without a nervous or nutritional supply. Therefore, there is a requirement to explore novel therapeutic means to retain the healthy teeth intact, without root canal therapy subsequent to the occurrence of pulp disease.

To efficiently recover damaged pulp, angiogenesis is a key step. Pulp is enriched vascularized tissue that protects against frequent inflammatory insults (3). Injured pulp cells secrete angiogenic growth factors to stimulate angiogenesis, which precedes reparative dentine formation (4). The dentine matrix contains angiogenic growth factors released from the matrix subsequent to injury to stimulate reparative responses in the dentine pulp complex (5). Angiogenesis is important for successful tissue regeneration, repair and healing; without adequate blood supply, tissue regeneration cannot be accomplished and necrotic or scar tissues are subsequently formed (6).

Vascular endothelial growth factor (VEGF) is the most potent angiogenic and vasculogenic factor involved in tertiary dentin formation. VEGF, an endothelium-specific secreted protein, serves an important role in angiogenesis (7). The VEGF family includes VEGF-A, -B, -C and -D, and these VEGFs have been reported to be expressed in human dental pulp, serving autocrine and paracrine roles in local blood vessels and immune cells $(8,9)$. Certain bacteria have been observed to upregulate VEGF-A (10), however severe inflammation can result in a reduction of the number of blood vessels and VEGF-A expression levels (8). A previous study identified that pulpal stem cells secrete VEGF during activation (11), and VEGF has been identified to induce proliferation and 
differentiation of human pulp cells into odontoblasts (12). These facts suggest that VEGF may be a useful growth factor in the repair of damaged pulp and dentin (12). The current study aimed to evaluate whether VEGF can be used in the treatment and prevention of dental pulp diseases.

\section{Materials and methods}

Cell culture. Normal exfoliated human deciduous incisors were collected from children aged 6-8 years old with the informed consent of patients and their parents, under the approved guidelines of China's bioethics law. The protocol was approved by the Research Ethics Review Committee of the School and Hospital of Stomatology, Jilin University (Changchun, China). The pulp was separated from a remnant crown and root and was washed with high glucose-Dulbecco's modified Eagle's medium (H-DMEM; Invitrogen; Thermo Fisher Scientific, Inc., Waltham, MA, USA) containing 1,000 units/ml penicillin and $1,000 \mu \mathrm{g} / \mathrm{ml}$ streptomycin (Invitrogen; Thermo Fisher Scientific, Inc.). The pulp was then cut into $\sim 0.5 \times 0.5 \times 0.5 \mathrm{~mm}$ tissue sections using sterilized eye scissors, placed into a $1.5 \mathrm{ml}$ tube and digested in a solution with $3 \mathrm{mg} / \mathrm{ml}$ collagenase type I (Invitrogen; Thermo Fisher Scientific, Inc.) and $4 \mathrm{mg} / \mathrm{ml}$ dispase (Invitrogen; Thermo Fisher Scientific, Inc.) for $15 \mathrm{~min}$ at $37^{\circ} \mathrm{C}$ in $5 \% \mathrm{CO}_{2}$. The human dental pulp cells (hDPCs) were pelleted by centrifugation at $82 \mathrm{xg}$ for $5 \mathrm{~min}$ at room temperature. The cell pellet was then re-suspended with H-DMEM with $20 \%$ fetal bovine serum (FBS; Invitrogen; Thermo Fisher Scientific, Inc.), 100 units/ml penicillin and $100 \mu \mathrm{g} / \mathrm{ml}$ streptomycin (Invitrogen; Thermo Fisher Scientific, Inc.). Subsequent to the first passage ( 10-15 days), the FBS concentration was reduced to $10 \%$. For all experiments in the current study, hDPCs from the third passage were used.

Adenoviral vector preparation. In the present study, subsequent to the deletion of the first generation of early-transcribed gene 1 , replication deficient adenovirus serotype 5 vectors, AdCMV-enhanced green fluorescent protein (EGFP) and AdCMV-hVEGF, were used (Clontech Laboratories, Inc., Mountainview, CA, USA). The two vectors were propagated in 293 cells, purified by $\mathrm{CsCl}$ (Sigma-Aldrich, St. Louis, MO, USA) gradient centrifugation using an Optima L-90K Ultracentrifuge (Beckman Coulter, Inc., Brea, CA, USA) and SW41 rotor (Beckman Coulter, Inc.) at $151,000 \mathrm{x} \mathrm{g}$ for $19 \mathrm{~h}$ at room temperature. They were dialyzed against 41 dialysis buffer containing $4 \%$ glycerol, $40 \mathrm{mM}$ Tris (pH 7.4) and $1 \mathrm{mM} \mathrm{MgCl}$ (Invitrogen; Thermo Fisher Scientific, Inc.) for $4 \mathrm{~h}$ at $4^{\circ} \mathrm{C}$ and then were stored in aliquots at $-80^{\circ} \mathrm{C}$ for later use. Vector titers were determined by reverse transcription-quantitative polymerase chain reaction (RT-qPCR) using transgene-specific primers.

Adipogenic induction assay in vitro. The hDPCs were seeded at $10^{5}$ cells/well in H-DMEM in 6-well plates and incubated at $37^{\circ} \mathrm{C}$ in a humidified $5 \% \mathrm{CO}_{2}$ atmosphere for $36 \mathrm{~h}$. A total of $0.5 \mathrm{mM}$ isobutylmethylxanthine, $1 \mu \mathrm{M}$ dexamethasone, $10 \mathrm{mg} / \mathrm{l}$ insulin (Sigma-Aldrich) and $200 \mu \mathrm{M}$ indomethacin (Qinghai Dadi Pharmaceutical Industry Co., Ltd., Xining, China) were then added and the cells were cultured for 5 weeks. The cell culture medium was replaced every 3 days.
On day 35, cells were fixed with $70 \%$ ethanol for $1 \mathrm{~h}$, washed with phosphate-buffered saline (PBS) once, stained with Oil Red O (Sigma-Aldrich) for $1 \mathrm{~h}$ at $37^{\circ} \mathrm{C}$, washed again and observed using an Olympus IX71 (Olympus Corporation, Tokyo, Japan).

Cell transduction efficiency with AdCMV-EGFP in vitro. The hDPCs were seeded at $5 \times 10^{4}$ cells/well in 12-well plates and incubated at $37^{\circ} \mathrm{C}$ in a humidified $5 \% \mathrm{CO}_{2}$ atmosphere for $36 \mathrm{~h}$. Subsequently, these cells were transduced with the recombinant adenovirus vector encoded with EGFP, AdCMV-EGFP, at $0,4,8$ or 10 multiplicity of infection (MOI)/cell. A total of 1 , 3, 5 and 7 days post-transduction, cells were directly observed under the Olympus IX71, transduction efficiency was calculated and the 3-(4,5-dimethylthiazol-2-yl)-2,5-diphenyltetrazolium bromide (MTT) colorimetric assay (Bio-Tek Instruments, Inc., Winooski, VT, USA) was performed.

VEGF expression by RT-PCR. The hDPCs were seeded at a density of $10^{5}$ cells/well in 6-well plates and were cultured for $36 \mathrm{~h}$. The cells were then transduced using AdCMV-EGFP or AdCMV-hVEGF at $10 \mathrm{MOI} / \mathrm{cell}$. On day 3, total RNA was extracted using TRIzol (Invitrogen; Thermo Fisher Scientific, Inc.). Total RNA $(1 \mu \mathrm{g})$ underwent a reverse transcription reaction using the PrimeScript ${ }^{\circledR}$ RT Reagent kit with gDNA Eraser (Takara Biotechnology Co., Ltd., Dalian, China) to synthesize cDNA. The hVEGFF1 (5'-AGAAGGAGGAGGGC AGAATC-3') and hVEGFB1 (5'-AATGCTTTCTCCGCT CTG-3') primers were used for the PCR reaction. RT reaction mixture $(1 \mu \mathrm{l})$ was used for the RT-PCR reaction. PCR assays

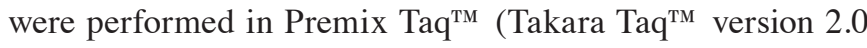
plus dye; Takara Biotechnology Co., Ltd.) using the Gene Amp ${ }^{\circledR}$ PCR System 9700 (Applied Biosystems; Thermo Fisher Scientific, Inc.) under the following conditions: $94^{\circ} \mathrm{C}$ for $5 \mathrm{~min}$, then 30 cycles of $94^{\circ} \mathrm{C}$ for $30 \mathrm{sec}, 55^{\circ} \mathrm{C}$ for $30 \mathrm{sec}$ and $72^{\circ} \mathrm{C}$ for $30 \mathrm{sec}$, followed by extension at $72^{\circ} \mathrm{C}$ for $5 \mathrm{~min}$. $\beta$-actin was used as the internal control. The PCR products were separated using $2 \%$ agarose gel electrophoresis, and were imaged with the Molecular Imager ${ }^{\circledR}$ Gel Doc ${ }^{\mathrm{TM}}$ XR System (Bio-Rad Laboratories, Inc., Hercules, CA, USA).

Alizarin red $S$ staining and alkaline phosphatase (ALP) activity assays in vitro. The hDPCs were seeded at $10^{5}$ cells/well in 6-well plates or at $10^{3}$ cells/well in 96-well plates, and were cultured for $36 \mathrm{~h}$, then transduced using AdCMV-EGFP or AdCMV-hVEGF at $10 \mathrm{MOI} / \mathrm{cell}$. One day post-transduction, culture medium was replaced with H-DMEM supplemented with $10 \%$ FBS, $10 \mathrm{mM} / 1$ sodium $\beta$-glycerol phosphate (Sigma-Aldrich), $50 \mathrm{mg} / 1$ L-ascorbic acid (Sigma-Aldrich) and $10^{-8} \mathrm{M} / 1$ dexamethasone (Sigma-Aldrich) to induce mineralization. On days 14 and 28, cells in the 6-well plates were washed with PBS and fixed in $95 \%$ ethanol at $4^{\circ} \mathrm{C}$ for $30 \mathrm{~min}$, then stained with $0.1 \%$ Alizarin red S (Sigma-Aldrich) at $37^{\circ} \mathrm{C}$ for $30 \mathrm{~min}$ and washed with $\mathrm{dH}_{2} \mathrm{O}$ five times.

The hDPCs in 96-well plates on days 3, 7, 14 and 21 were used to detect cell ALP activity using the ALP substrate (Sigma-Aldrich) and plates were read with an ELx800 Absorbance Reader (Bio-Tek Instruments, Inc.) at a wavelength of $520 \mathrm{~nm}$ according to the manufacturer's instructions. 
A

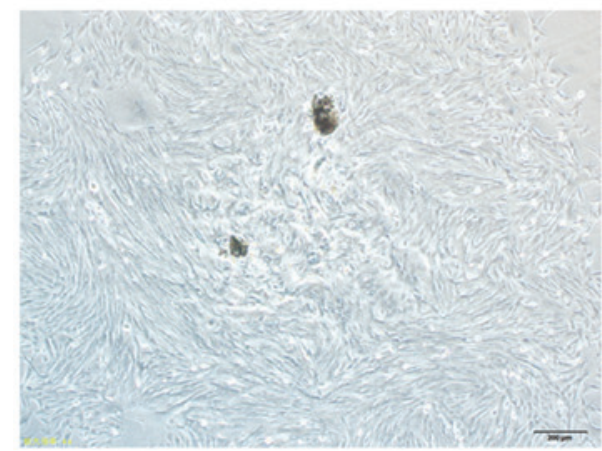

D

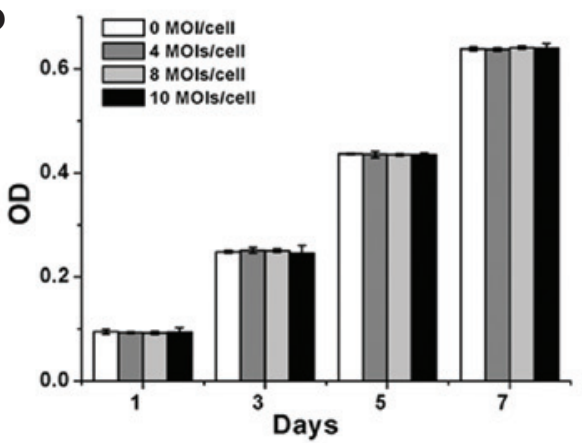

B

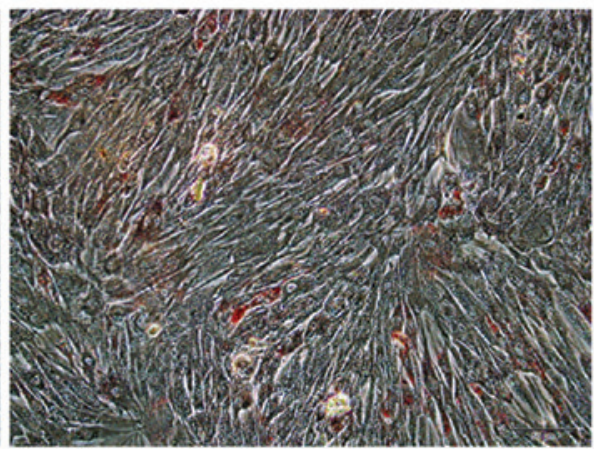

C

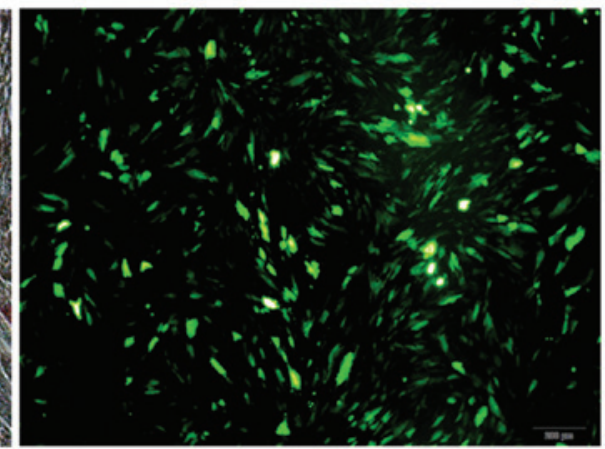

E

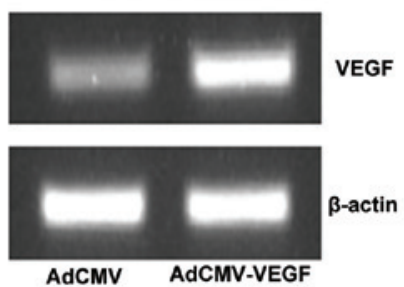

AdCMV

AdCMV-VEG

Figure 1. Characteristics of hDPCs. (A) hDPCs were cultured for 3 days. (B) hDPCs were stained with Oil Red O subsequent to culture in adipogenic medium for 5 weeks. (C) hDPCs were cultured for 3 days subsequent to 3 days post-transduction with AdCMV-EGFP at 10 MOI/cells. (D) 3-(4,5-dimethylthiazol-2-yl)2,5-diphenyltetrazolium bromide proliferation assays of hDPCs transduced with AdCMV-EGFP from 0-10 MOI/cell. (E) hVEGF expression data from the reverse-transcription polymerase chain reaction assay subsequent to the transduction of hDPCs with AdCMV-hVEGF at $10 \mathrm{MOI} / \mathrm{cell}$ on day 3. hDPCs, human dental pulp cells; MOI, multiplicity of infection; EGFP, enhanced green fluorescent protein; hVEGF, human vascular endothelial growth factor; OD, optical density.

RT- $q P C R$ in vitro. Total RNA was extracted as described above on days 3, 7 and 14 by TRIzol. Total RNA ( $6 \mu \mathrm{g})$ was used for the reverse transcription reaction using the PrimeScript ${ }^{\circledR}$ RT Reagent kit with gDNA Eraser. RT reaction mixture $(1 \mu \mathrm{l})$ was used for qPCR. Primers and probes for bone morphogenetic protein 2 (BMP2), runt-related transcription factor 2 (Runx2), ALP, collagen type I $\alpha(\mathrm{Col} 1 \alpha)$, bone sialoprotein (BSP), Sp7, dentin matrix acidic phosphoprotein 1 (DMP1), osteocalcin $(\mathrm{OCN})$ and dentin sialophosphoprotein (DSPP) were obtained from Thermo Fisher Scientific, Inc. All qPCR assays were performed using the MX3005P system (Agilent Technologies, Inc., Santa Clara, CA, USA) using TaqMan ${ }^{\circledR}$ Universal PCR Master Mix (Applied Biosystems; Thermo Fisher Scientific, Inc.) under the following conditions: $50^{\circ} \mathrm{C}$ for $2 \mathrm{~min}, 95^{\circ} \mathrm{C}$ for $10 \mathrm{~min}$, then 40 cycles of $95^{\circ} \mathrm{C}$ for $15 \mathrm{sec}$ and $60^{\circ} \mathrm{C}$ for $1 \mathrm{~min}$. $\beta$-actin was used as the internal control.

In vivo animal assays. The animal experimental protocol was approved by the Institutional Animal Care and Use Committee and the Ethics Committee of the Faculty of Dentistry, Jilin University (Changchun, China). A total of 30 upper first molars from 15 specific pathogen-free male Wistar rats ( $200 \mathrm{~g}, 2$ months old) were used in the current study (Animal Experimental Center of Jilin University). Rats were anesthetized with ketamine $(60 \mathrm{mg} / \mathrm{kg}$; Jiangsu Hengrui Medicine Co., Ltd., Lianyungang, China) and xylazine ( $8 \mathrm{mg} / \mathrm{kg}$; Sigma-Aldrich). The coronal enamel and dentin of the first molar were carefully removed from the occlusal surface with stainless steel burs under water cooling to expose the pulp using an endodontic microscope (OPMI ${ }^{\circledR}$ pico; Carl Zeiss AG, Oberkochen, Germany). Subsequent to washing the pulp with saline, a gelatin sponge containing AdCMV-EGFP or AdCMV-hVEGF at $1.25 \times 10^{4} \mathrm{MOI} / 0.25 \mu \mathrm{l}$ was applied to the exposed pulp surface on the left or right side. The two adenoviral vectors were then released and transduced into adjacent dental pulp cells. The occlusal cavities were sealed with GC Fuji IX GP (GC Corporation, Tokyo, Japan). On days 3, 7 and 14 subsequent to surgery, animals were anesthetized with ketamine $(60 \mathrm{mg} / \mathrm{kg})$ and xylazine $(8 \mathrm{mg} / \mathrm{kg})$ and euthanized by intracardiac perfusion with a $4 \%$ paraformaldehyde buffered solution (Beijing Chemical Works, Beijing, China). The upper molars were excised and fixed with $4 \%$ paraformaldehyde for two days, decalcified in 10\% ethylenediaminetetraacetic acid (EDTA; Beijing Chemical Works, Beijing, China) for three months at room temperature, then rinsed in water, dehydrated in a series of increasing concentrations of alcohol, embedded in paraffin and cut into $3 \mu \mathrm{m}$ sections using a rotary microtome (RM2245; Leica Biosystems, Buffalo Grove, IL, USA). Sections were stained with hematoxylin and eosin (Ameresco, Inc., Framingham, MA, USA) or immunohistochemical staining.

Immunohistochemical analysis. Subsequent to deparaffinization, the sections were treated with compound enzyme digestive juice $(0.125 \%$ trypsin $+0.1 \%$ pepsin $+0.01 \%$ EDTA; Wuhan Boster Biological Technology, Ltd., Wuhan, China) for $20 \mathrm{~min}$ and then with antigen retrieval solution (Wuhan 
A

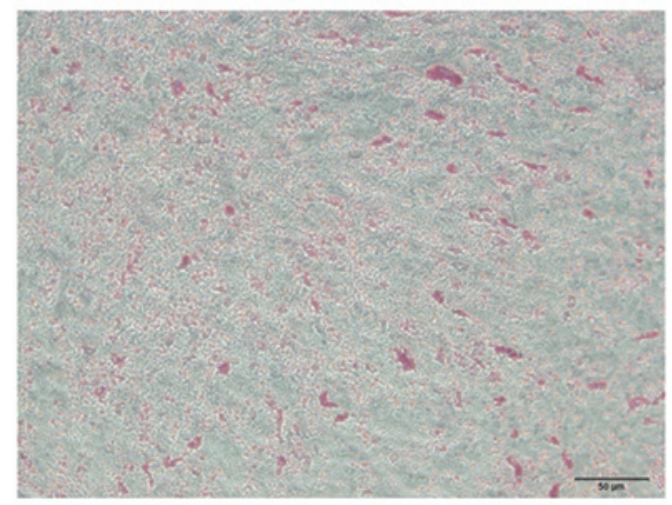

C

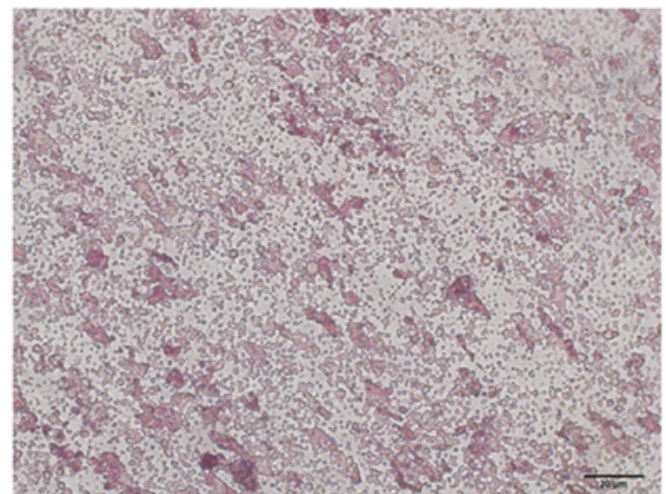

B

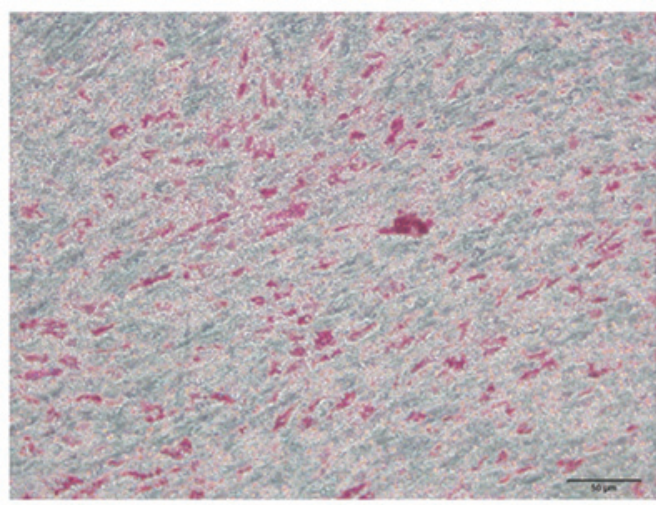

D

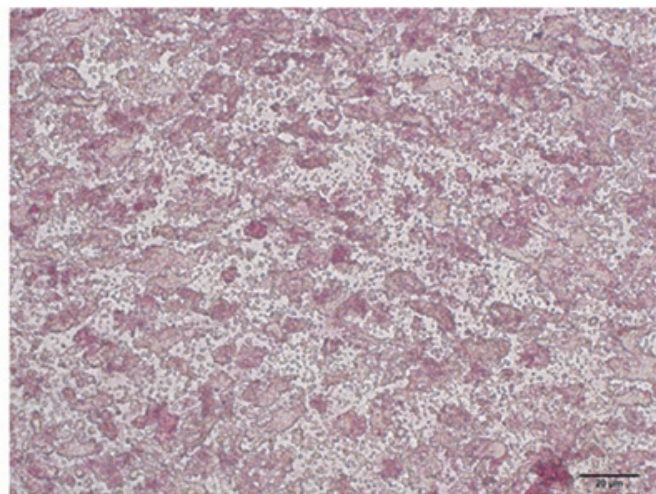

E

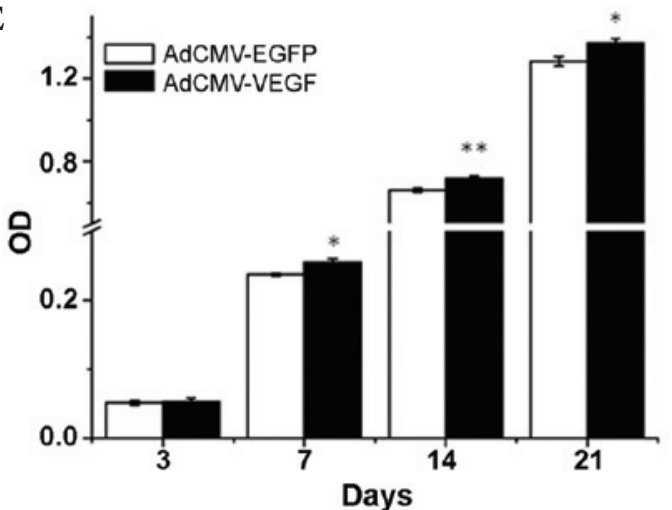

Figure 2. Evidence of differentiation and mineralization by Alizarin red S staining and ALP activity. (A) hDPCs transduced with AdCMV-EGFP 14 days post-transduction. (B) hDPCs transduced with AdCMV-hVEGF 14 days post-transduction. (C) hDPCs transduced with AdCMV-EGFP 28 days post-transduction. (D) hDPCs transduced with AdCMV-hVEGF 28 days post-transduction. (E) ALP activity from hDPCs transduced with AdCMV-EGFP or AdCMV-hVEGF. Data are presented as the mean \pm standard error. The assays were repeated three times. " $\mathrm{P}<0.05$ and ${ }^{* *} \mathrm{P}<0.01$ vs. AdCMV-EGFP. ALP, alkaline phosphatase; hDPCs, human dental pulp cells; EGFP, enhanced green fluorescent protein; hVEGF, human vascular endothelial growth factor; OD, optical density.

Boster Biological Technology, Ltd.) for 10 min. The immunohistochemistry was performed according to the instructions of UltraSensitive ${ }^{\mathrm{TM}} \mathrm{SP}$ (mouse/rabbit) immunohistochemistry kit (Maixin-Bio, Fuzhou, China). The anti-rat mouse monoclonal DMP1-C-8 G 10.3 and anti-rat mouse monoclonal anti-DSP-2C12.3 antibodies (donated by Dr Chunlin Qin, Baylor College of Dentistry, Texas A\&M University Health Science Center, Dallas, TX, USA) $(13,14)$ at a dilution of 1:1,000 used as the primary antibodies (15). The sections were then observed under a microscope (Olympus BX51TF; Olympus Corporation).

Statistical analysis. Results were presented as the mean \pm standard error. A paired t-test was used to determine the statistical significance. $\mathrm{P}<0.05$ was considered to indicate a statistically significant difference.

\section{Results}

Characteristics of hDPCs from exfoliated deciduous teeth. In the current study, hDPC culture was established following Miura's method (16). Fig. 1A presents the general morphology of hDPCs on day 3 under the inverted microscope. In general, hDPCs were cultured for 10-15 days, then passaged three times ( 5 days/passage). Cells from the third passage were used for the experiments. When the cells were cultured in $0.5 \mathrm{mM}$ isobutylmethylxanthine, $1 \mu \mathrm{M}$ dexamethasone, $10 \mathrm{mg} / \mathrm{l}$ insulin and $200 \mu \mathrm{M}$ indomethacin for 5 weeks, certain cells were observed to be Oil Red O positive (Fig. 1B), which indicates that adipogenic differentiation had occurred.

To evaluate the transduction efficiency of the adenoviral vector, hDPCs were transduced with AdCMV-EGFP at $10 \mathrm{MOI} / \mathrm{cell}$. Approximately $70 \%$ of the hDPCs were identified 

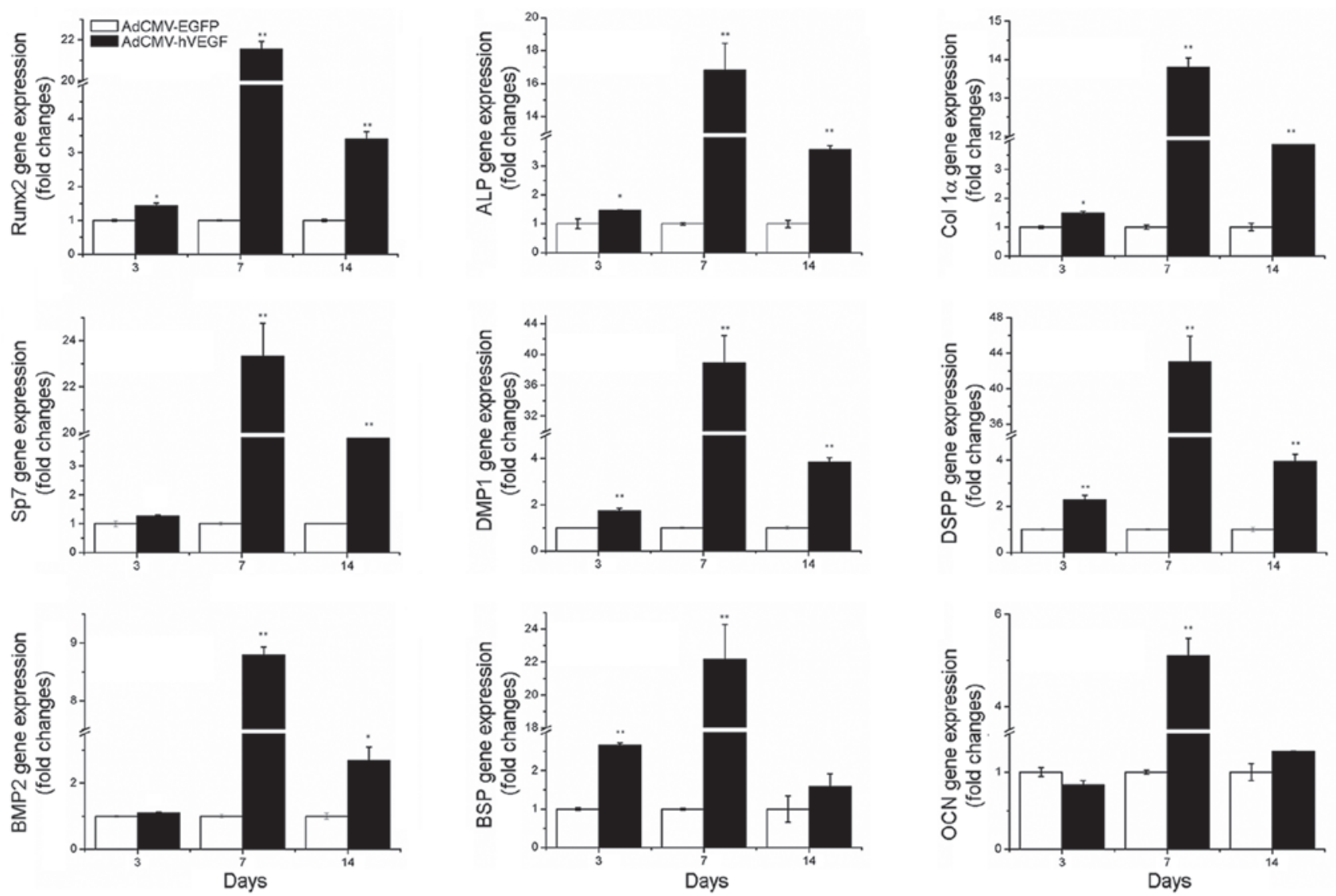

Figure 3. Gene expression profiles of hDPCs transduced with AdCMV-EGFP or AdCMV-hVEGF 3, 7 or 14 days post-transduction. Data are presented as the mean \pm standard error. The assays were repeated three times. ${ }^{*} \mathrm{P}<0.05$ and ${ }^{* *} \mathrm{P}<0.01$ vs. AdCMV-EGFP. hDPCs, human dental pulp cells; EGFP, enhanced green fluorescent protein; hVEGF, human vascular endothelial growth factor; Runx2, runt-related transcription factor 2; ALP, alkaline phosphatase; Col 1 $\alpha$, collagen type I $\alpha$; DMP1, dentin matrix acidic phosphoprotein 1; DSPP, dentin sialophosphoprotein; BMP2, bone morphogenetic protein 2; BSP, bone sialoprotein; OCN, osteocalcin.

as being EGFP-positive on day 3 (Fig. 1C). Subsequently, MTT assays were conducted in order to assess whether the adenoviral vector affected the proliferation of hDPCs. Fig. 1D demonstrates that the adenoviral vector, AdCMV-EGFP, did not influence the proliferation of hDPCs from 0 to $10 \mathrm{MOI} / \mathrm{cell}$. VEGF expression was also measured, and was observed to be increased subsequent to transduction of the hDPCs with AdCMV-hVEGF at $10 \mathrm{MOI} / \mathrm{cell}$ (Fig. 1E). This indicated that these adenoviral vectors could be used to transduce these cells.

Effects of hVEGF on hDPCs differentiation. Alizarin red S staining and ALPactivity were the two indicators used to monitor the differentiation of hDPCs in the culture media in the current study. Data demonstrated that calcium deposition occurred in the hDPCs, whereas the AdCMV-hVEGF-treated group had a significantly greater number of Alizarin red S-positive cells or mineralized nodules on days 14 and 28 compared with that of the AdCMV-EGFP control group (Fig. 2A-D). hVEGF was identified to significantly increase ALP activity 7 days post-transduction (Fig. 2E). These results demonstrate that VEGF is able to promote the mineralization and differentiation of hDPCs.

Effects of hVEGF on gene expression following mineralization induction. To further understand the effects of hVEGF on the differentiation of hDPCs at the molecular level, RT-qPCR assays were conducted to quantitatively evaluate gene expression of nine osteogenic/odontogenic gene markers: Runx2, ALP, Col 1 $\alpha$, SP7, DMP1, DSPP, BMP2, BSP and OCN. Data in Fig. 3 indicates that hVEGF significantly increased the expression of these genes when compared with the AdCMV-EGFP group on days 7 and 14, particularly on day 7. This indicates that VEGF is able to affect osteoblasts/odontoblasts.

Direct effects of $h V E G F$ on reparative dentin formation in vivo. The above-mentioned in vitro data demonstrated that VEGF was able to affect differentiation and mineralization of hDPCs. Subsequently, in vivo assays to investigate whether hVEGF directly affects pulp cells in vivo were undertaken. The collected data demonstrated that the AdCMV-hVEGF-treated groups had a marked increase in the number of blood vessels in the dental pulp compared with the AdCMV-EGFP-treated group on days 3, 7 and 14 (Fig. 4A-F). The results additionally identified that hVEGF was able to increase the volume of reparative dentin compared with the AdCMV-EGFP-treated groups on days 7 and 14 (Fig. 4C-F). In addition, it was observed by immunohistochemical staining that the AdCMV-hVEGF-treated groups exhibited stronger DMP1 and DSP-positive pulp cells than in the AdCMV-EGFP-treated groups (Fig. 4G-J), which indicated that the pulp cells actively proliferate in AdCMV-hVEGF-treated dental pulp. 
A

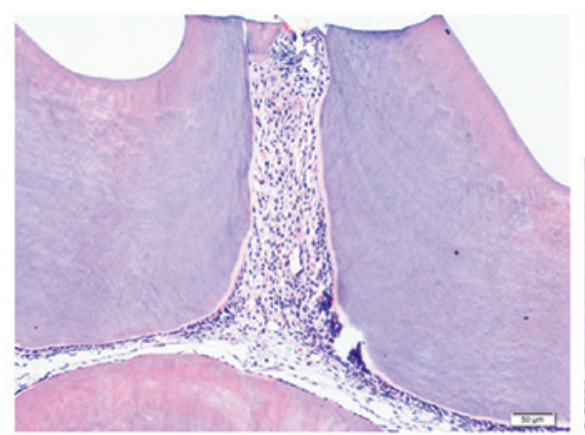

B

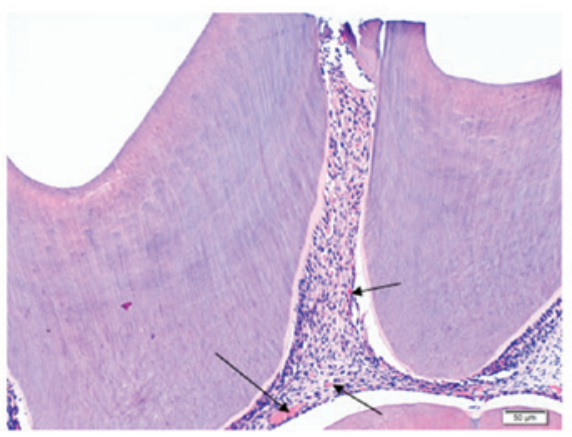

C

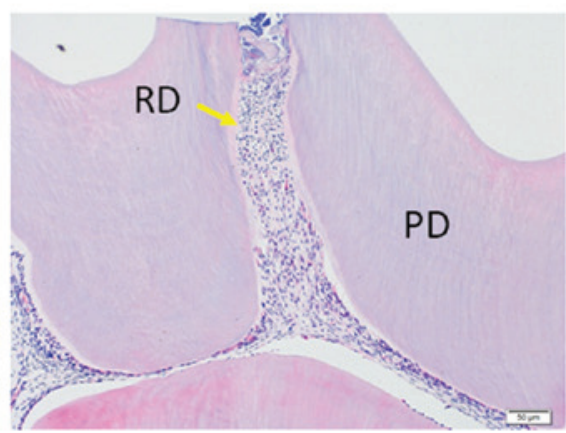

$\mathbf{E}$
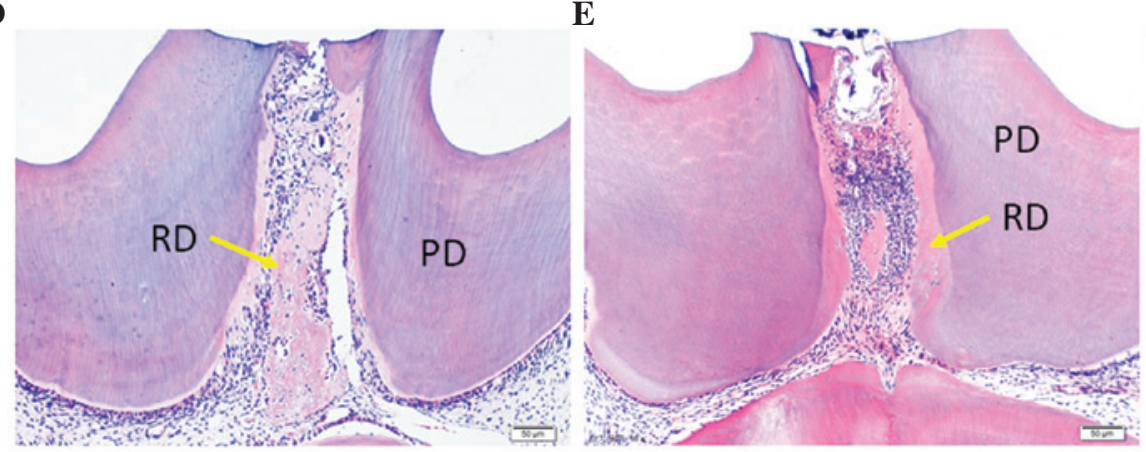

$\mathbf{F}$
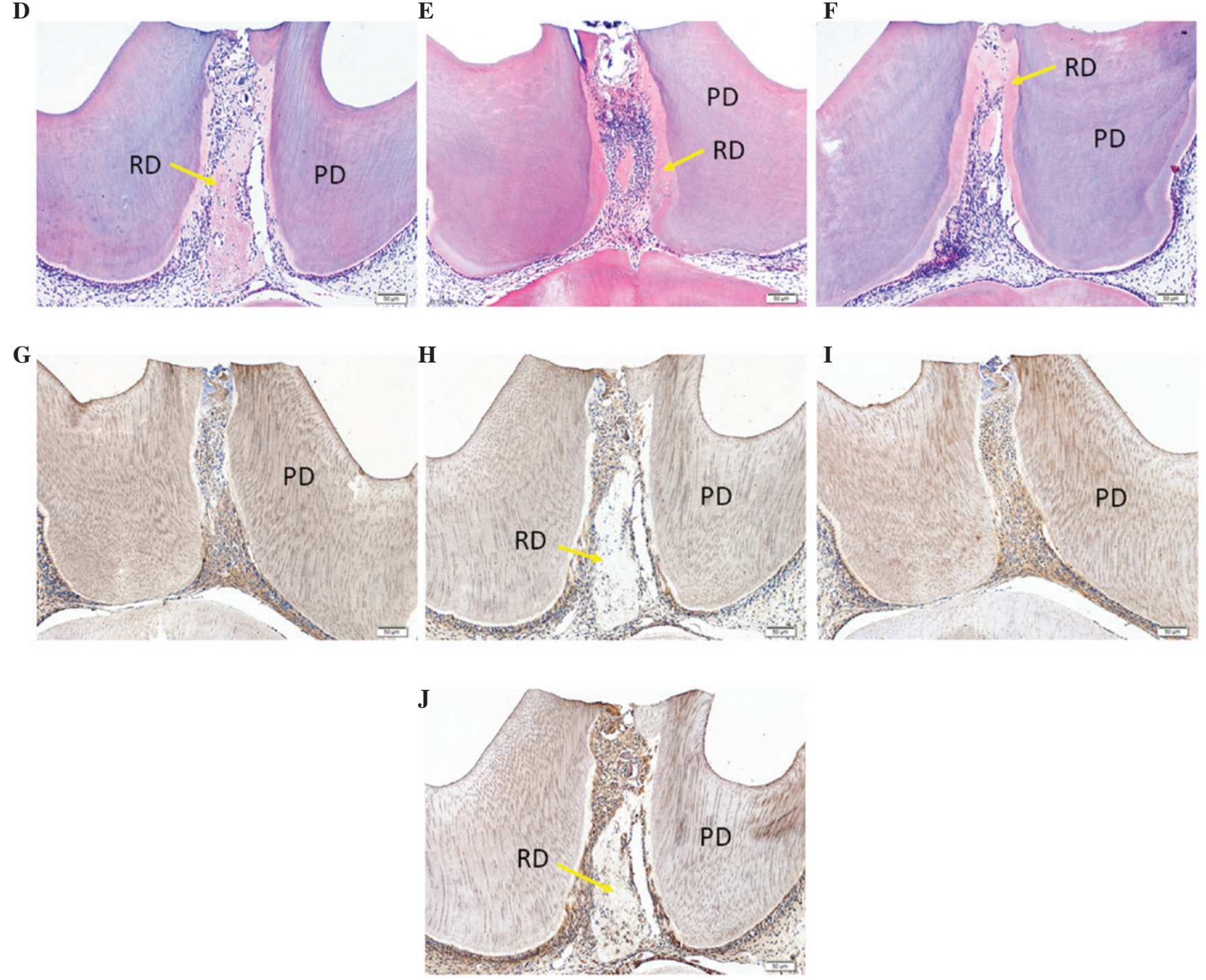

Figure 4. Effects of hVEGF on RD formation in vivo via (A-F) hematoxylin and eosin and (G-J) immunohistochemical staining. (A) AdCMV-EGFP group 3 days post-transduction. (B) AdCMV-hVEGF group 3 days post-transduction. (C) AdCMV-EGFP group 7 days post-transduction. (D) AdCMV-hVEGF group 7 days post-transduction. (E) AdCMV-EGFP group 14 days post-transduction. (F) AdCMV-hVEGF group 14 days post-transduction. (G) DMP1 staining of the AdCMV-EGFP group 7 days post-transduction. (H) DMP1 staining of the AdCMV-hVEGF group 7 days post-transduction. (I) DSP staining of the AdCMV-EGFP group 7 days post-transduction. (J) DSP staining of the AdCMV-hVEGF group 7 days post-transduction. Black arrows indicate blood vessels, yellow arrows indicate RD. hVEGF, human vascular endothelial growth factor; EGFP, enhanced green fluorescent protein; DMP1, dentin matrix acidic phosphoprotein 1; DSP; dentin sialoprotein; DSPP, dentin sialophosphoprotein; PD, primary dentin; RD, reparative dentin.

\section{Discussion}

The body's vascular system supports the critical functions of supplying cells and tissues with nutrients and clearing away waste products. Vascular permeability is markedly increased in cases of acute and chronic inflammation such as those in pulpitis $(17,18)$. Endotoxins produced by cariogenic bacteria stimulate VEGF expression in dental pulp cells (19), and VEGF 
is a key regulator in the response to pulp injury resulting in increases in vascular permeability and angiogenesis during the healing process $(10,20)$. The results of the current study demonstrated that VEGF is able to promote proliferation and differentiation of pulp cells in vitro and in vivo.

A previous study reported that stem cells from human exfoliated deciduous teeth expressed the membrane-bound VEGF receptors (VEGFR)-1 and -2, CD31 and vascular endothelial-cadherin (11). An additional study reported that VEGF was able to stimulate proliferation and increase ALP in human pulp cells (8). It has been widely reported that the gene expression levels of Runx-2 and ALP serve important roles in the early and middle stages of differentiation during bone formation, whereas expression of BSP, OPN and OCN serve critical roles in the late stages of osteoblast differentiation (21). The DSPP gene produces two key noncollagenous dentin proteins: Dentin sialoprotein and dentin phosphoprotein, which are essential for dentin mineralization $(22,23)$. DMP-1 is predominantly expressed in odontoblasts and is a candidate gene for dentinogenesis imperfecta (24). Notably, the data of the current study demonstrated that VEGF may promote the mineralization and differentiation of hDPCs (Fig. 2) and markedly increase gene expression of Runx2, ALP, Col 1 $\alpha$, SP7, DMP1, DSPP, BMP2, BSP and OCN in pulp cell culture in vitro (Fig. 3 ). Therefore, the data of the present study suggests that VEGF is able to enhance osteoblast/odontogenic differentiation and mineralization of hDPCs in vitro.

Reparative dentin is a type of tertiary dentin (reactionary and reparative dentin), which functionally responds to severe injury and is formed by replacement odontoblasts (25). Angiogenesis serves a key role in tissue regeneration due to the requirements of nutrient supply and waste removal for the functioning of a vascular network (26). Pulp tissue normally only receives blood supply from one end, at the root apex, therefore, dental pulp tissue is vulnerable to damage, infection and the development of irreversible pulpitis (26). Applying angiogenic growth factors locally has been suggested to increase local angiogenesis at the site of dental tissue repair subsequent to tooth root fracture (27). Numerous studies have applied different strategies for the promotion of angiogenesis for their disease model (28-30). Mullane et al (31) demonstrated that recombinant hVEGF (165) was able to enhance the neovascularization of human dental pulp. In vivo data from the current study additionally demonstrated that hVEGF may increase proliferation of dental pulp and promote neovascularization and formation of reparative dentin in the dental pulp.

In conclusion, the current study demonstrates that hVEGF has positive influences on proliferation, differentiation, mineralization, neovascularization and formation of reparative dentin of dental pulp tissue in vitro and in vivo. The data collected strongly suggest that hVEGF has clinical therapeutic potential for the treatment of pulp diseases. The current study additionally suggests that a gene therapy strategy may be useful for treatment of dental pulp diseases. As a next step, hVEGF and inhibitors of inflammation will be used in order to investigate whether it is possible to treat reversible and irreversible pulpitis, with a particular focus on irreversible pulpitis.

\section{Acknowledgements}

The authors would like to thank Dr Chunlin Qin (Baylor College of Dentistry, Texas A\&M University Health Science Center, Dallas, TX, USA) for the donation of the DMP1 and DSP antibodies and Ms. Cindy Clark (NIH Library Editing Service, Bethesda, MD, USA) for reviewing the manuscript. The current study was supported by the Science and Technology Development Projects of Jilin Province (grant no. 20140204018SF), Jilin Provincial Health Department Research Projects (grant no. 2012S017), the Fundamental Research Project of the Central Universities (grant no. 450060491132), the 2013 Human Resources and Social Security Development Postdoctoral Research Projects of Jilin Province (grant no. 20130419431) and the National Natural Science Foundation of China (grant no. 81271111).

\section{References}

1. Couve E, Osorio R and Schmachtenberg O: Reactionary dentinogenesis and neuroimmune response in dental caries. J Dent Res 93: 788-793, 2014.

2. Farges JC, Joffre A and Magloire H: Response of odontoblastic and pulpal cells to carious lesions. C R Seances Soc Biol Fil 187: 582-595, 1992 (In French).

3. Bjørndal L and Mjör IA: Pulp-dentin biology in restorative dentistry. Part 4: Dental caries-characteristics of lesions and pulpal reactions. Quintessence Int 32: 717-736, 2001.

4. Tran-Hung L, Laurent P, Camps J and About I: Quantification of angiogenic growth factors released by human dental cells after injury. Arch Oral Biol 53: 9-13, 2008.

5. Roberts-Clark DJ and Smith AJ: Angiogenic growth factors in human dentine matrix. Arch Oral Biol 45: 1013-1016, 2000.

6. Madeddu P: Therapeutic angiogenesis and vasculogenesis for tissue regeneration. Exp Physiol 90: 315-326, 2005.

7. Hood JD, Meininger CJ, Ziche M and Granger HJ: VEGF upregulates ecNOS message, protein, and NO production in human endothelial cells. Am J Physiol 274: H1054-H1058, 1998.

8. Artese L, Rubini C, Ferrero G, Fioroni M, Santinelli A and Piattelli A: Vascular endothelial growth factor (VEGF) expression in healthy and inflamed human dental pulps. J Endod 28: 20-23, 2002.

9. Virtej A, Løes S, Iden O, Bletsa A and Berggreen E: Vascular endothelial growth factors signalling in normal human dental pulp: A study of gene and protein expression. Eur J Oral Sci 121: 92-100, 2013

10. Soden RI, Botero TM, Hanks CT and Nör JE: Angiogenic signaling triggered by cariogenic bacteria in pulp cells. J Dent Res 88: 835-840, 2009.

11. Sakai VT, Zhang Z, Dong Z, Neiva KG, Machado MA, Shi S, Santos CF and Nör JE: SHED differentiate into functional odontoblasts and endothelium. J Dent Res 89: 791-796, 2010.

12. Matsushita K, Motani R, Sakuta T, Yamaguchi N, Koga T, Matsuo K, Nagaoka S, Abeyama K, Maruyama I and Torii M: The role of vascular endothelial growth factor in human dental pulp cells: Induction of chemotaxis, proliferation and differentiation and activation of the AP-1-dependent signaling pathway. $\mathrm{J}$ Dent Res 79: 1596-1603, 2000.

13. Huang B, Maciejewska I, Sun Y, Peng T, Qin D, Lu Y, Bonewald L, Butler WT, Feng J and Qin C: Identification of full-length dentin matrix protein 1 in dentin and bone. Calcif Tissue Int 82: 401-410, 2008.

14. Baba O, Qin C, Brunn JC, Jones JE, Wygant JN, McIntyre BW and Butler WT: Detection of dentin sialoprotein in rat periodontium. Eur J Oral Sci 112: 163-170, 2004

15. Moses KD, Butler WT and Qin C: Immunohistochemical study of small integrin-binding ligand, $\mathrm{N}$-linked glycoproteins in reactionary dentin of rat molars at different ages. Eur J Oral Sci 114: 216-222, 2006.

16. Miura M, Gronthos S, Zhao M, Lu B, Fisher LW, Robey PG and Shi S: SHED: Stem cells from human exfoliated deciduous teeth. Proc Natl Acad Sci USA 100: 5807-5812, 2003. 
17. Nagy JA, Benjamin L, Zeng H, Dvorak AM and Dvorak HF: Vascular permeability, vascular hyperpermeability and angiogenesis. Angiogenesis 11: 109-119, 2008.

18. Heyeraas KJ and Berggreen E: Interstitial fluid pressure in normal and inflamed pulp. Crit Rev Oral Biol Med 10: 328-336, 1999.

19. Botero TM, Shelburne CE, Holland GR, Hanks CT and Nör JE: TLR4 mediates LPS-induced VEGF expression in odontoblasts. J Endod 32: 951-955, 2006.

20. Botero TM, Son JS, Vodopyanov D, Hasegawa M, Shelburne CE and Nör JE: MAPK signaling is required for LPS-induced VEGF in pulp stem cells. J Dent Res 89: 264-269, 2010.

21. Mangano C, Paino F, d'Aquino R, De Rosa A, Iezzi G, Piattelli A, Laino L, Mitsiadis T, Desiderio V, Mangano F, et al: Human dental pulp stem cells hook into biocoral scaffold forming an engineered biocomplex. PLoS One 6: e18721, 2011.

22. Feng JQ, Luan X, Wallace J, Jing D, Ohshima T, Kulkarni AB, D'Souza RN, Kozak CA and MacDougall M: Genomic organization, chromosomal mapping and promoter analysis of the mouse dentin sialophosphoprotein (Dspp) gene, which codes for both dentin sialoprotein and dentin phosphoprotein. J Biol Chem 273: 9457-9464, 1998.

23. MacDougall M, Gu TT and Simmons D: Dentin matrix protein-1, a candidate gene for dentinogenesis imperfecta. Connect Tissue Res 35: 267-272, 1996.
24. Suzuki S, Sreenath T, Haruyama N, Honeycutt C, Terse A, Cho A, Kohler T, Müller R, Goldberg M and Kulkarni AB: Dentin sialoprotein and dentin phosphoprotein have distinct roles in dentin mineralization. Matrix Biol 28: 221-229, 2009.

25. Mitsiadis TA and Rahiotis C: Parallels between tooth development and repair: Conserved molecular mechanisms following carious and dental injury. J Dent Res 83: 896-902, 2004.

26. Huang GT: Pulp and dentin tissue engineering and regeneration: Current progress. Regen Med 4: 697-707, 2009.

27. Jin H, Thomas HF and Chen J: Wound healing and revascularization: A histologic observation of experimental tooth root fracture. Oral Surg Oral Med Oral Pathol Oral Radiol Endod 81: 26-30, 1996.

28. Kanematsu A, Yamamoto S, Ozeki M, Noguchi T, Kanatani I, Ogawa $\mathrm{O}$ and Tabata Y: Collagenous matrices as release carriers of exogenous growth factors. Biomaterials 25: 4513-4520, 2004.

29. Peters MC, Polverini PJ and Mooney DJ: Engineering vascular networks in porous polymer matrices. J Biomed Mater Res 60: 668-678, 2002

30. Sun Q, Chen RR, Shen Y, Mooney DJ, Rajagopalan S and Grossman PM: Sustained vascular endothelial growth factor delivery enhances angiogenesis and perfusion in ischemic hind limb. Pharm Res 22: 1110-1116, 2005.

31. Mullane EM, Dong Z, Sedgley CM,Hu JC, Botero TM, Holland GR and Nör JE: Effects of VEGF and FGF2 on the revascularization of severed human dental pulps. J Dent Res 87: 1144-1148, 2008. 